\title{
Challenges Faced by the Patients on Dialysis Treatment in COVID-19 Era and the Possible Solutions
}

\author{
Sajid Iqbal' ${ }^{1}$, Aimen Iqbal ${ }^{2}$, Keron Akintola Ayodele Blair ${ }^{3}$, Behzad Saeed Gill ${ }^{4}$, Fesih Muhammad \\ Waseem $^{5}$, Umair Syed Mahmud ${ }^{5}$, Muhammad Jahanzaib Khan ${ }^{5}$, Abdullah Ali ${ }^{5}$, Anjli Tara ${ }^{6}$, \\ Mahnoor Aitzaz Khan ${ }^{5}$, Muhammad Muneeb Arshad ${ }^{5}$, Haris Aleem ${ }^{5}$, Tetiana Medvid ${ }^{7}$, \\ Muhammad Bilal Ahmed ${ }^{8}$, Erjola Bidika ${ }^{9}$, Meklit Zenbabaw Hunde ${ }^{10}$, Khadija Nasim $^{11}$ and \\ Nadeem Iqbal ${ }^{12 *}$
}

${ }^{1}$ Department of Rehabilitation, PNS Hospital Karachi, Pakistan

${ }^{2}$ Bahria University Medical and Dental College, Pakistan

${ }^{3}$ American International School of Medicine, Georgetown Guyana

${ }^{4}$ Shifa International Hospital, Pakistan

${ }^{5}$ Shifa College of Medicine, Pakistan

${ }^{6}$ Liaqat University of Medical and Health Sciences, Jamshoro

${ }^{7}$ Danylo Halytsky Lviv, National Medical University, Ukraine

${ }^{8}$ Dow International Medical College, Pakistan

${ }^{9}$ University of Medicine of Tirana, Albania

${ }^{10}$ Mekelle University College of Health Science, Ethiopia

${ }^{11}$ Jinnah Sindh Medical University, Pakistan

${ }^{12}$ Department of Urology and Kidney Transplant, Pakistan Kidney and Liver Institute Lahore, Pakistan

*Corresponding author: Nadeem Iqbal, Department of Urology and Kidney Transplant, Pakistan Kidney and Liver Institute Lahore, Pakistan

\section{ARTICLE INFO}

Received: May 13, 2021

Published: 慧 June 01, 2021

Citation: Sajid Iqbal, Aimen Iqbal, Keron Akintola Ayodele Blair, Behzad Saeed Gill, Nadeem Iqbal, et al., Challenges Faced by the Patients on Dialysis Treatment in COVID-19 Era and the Possible Solutions. Biomed J Sci \& Tech Res 36(2)-2021. BJSTR. MS.ID.005812.

\begin{abstract}
The current COVID-19 situation has resulted in disruptions in the social, economic and health care system throughout the world. Lock down have been implemented due to need for social distancing practices across the globe. One such challenge is faced by patients of End stage renal disease (ESRD). They have to be physically present in hemodialysis center on regular basis, which means they are more at risk of exposure in a hospital environment. They are in close contact with multiple people for the purpose of dialysis. The pandemic has entailed an enormous burden upon the hospital management and the healthcare workers because of limited staff availability during this pandemic. Aim of this study was to review literature regarding the special aspects and challenges pertaining to those patients who are on regular dialysis treatment.
\end{abstract}

Keywords: Pandemic; COVID-19; Dialysis Clinic; Infection Control; Telemedicine Clinic

Abbreviations: COVID-19: Coronavirus Disease; SARS-CoV-2: Severe Acute Respiratory Syndrome Coronavirus 2; ARDS: Acute Respiratory Distress Syndrome; ESRD: End Stage Renal Disease 


\section{Introduction}

Coronavirus disease (COVID-19), assignable to severe acute respiratory syndrome coronavirus 2 (SARS-CoV-2), that emanated from Wuhan City in 2019. Since then, it has incited a pandemic. Most cases present with mild symptoms including fever, sore throat, cough, fatigue, myalgia, diarrhea, nausea, loss sense of smell, and abdominal pain [1-3]. Having said that, it is also a fact that in few cases, patients might manifest with severe presentation of pneumonia, respiratory failure caused by acute respiratory distress syndrome (ARDS), other multi-organ failure such as myocarditis, advanced renal failure, and even death in catastrophic cases [4-8]. COVID-19 has shown an enormous potential to spread like a fire, with resultant morbidity and mortality on a global scale. Lock down have been implemented due to need for social distancing practices throughout the world. This has been demanding when it comes to providing healthcare services [3-6]. One such challenge is faced by patients of End stage renal disease (ESRD). They have to be physically present in hemodialysis center on regular basis, which means they are more at risk of exposure in a hospital environment [4-7].

They are in close contact with multiple people from the time they depart from their homes till the time they reach back, including drivers, and once inside the center, with nurses, technicians, nephrologists, and other patients for about 4-5 hours. Additionally, such patients are having multiple comorbid conditions, endangering them further to contract the infection [4-10]. The pandemic has entailed an enormous burden upon the hospital management and the healthcare workers because of limited staff availability during this pandemic [11-14]. Owing to scarcity of knowledge of the SARS-CoV-2 natural history, problem of the asymptomatic carriers, international travelers, paucity of optimum treatment, risks of reinfection, and overstretched global health systems have resulted in huge challenge to tackle it and curb it effectually. The net outcomes are inferior in elder patients, patients who have comorbidities and especially male gender. Aim of this study was to review literature regarding the special aspects and challenges pertaining to those patients who are on regular dialysis treatment.

\section{Methods}

We did search on PubMed, Medline database publications using: COVID-19, Dialysis clinic, infection control, and telemedicine clinic. The publications included were special communications, reviews, conferences papers, books and research studies regarding the subject matter over last one year.

\section{Discussion}

People with advanced CKD constitute an important vulnerable group in this regard, as they've to undergo multiple dialysis interventions in advanced healthcare settings (they usually visit dialysis clinics two to three times a week for an average of four hours at a time, exposing themselves to other patients and, potentially, the virus). As the risk of virus transmission itself, is increased by multiple visits to the hospitals, exposure to doctors, and the presence of other patients; so multiple ways to limit this interaction have been suggested and implemented. One such strategy is a delay in initiation of renal replacement treatment if practicable (wait for the COVID-19 swab results before commencement of dialysis). This will avoid the stress of concerns regarding the safety of staff and resultant conservation of PPE stock- which has had a strained supply during the pandemic [6-10]. Usage of loop diuretics and potassium binders can help in delaying the necessity for RRT commencement. Some other intelligent measures can be taken such as placing the dialysis machines outside the patient's roomwhile giving a safe and secure passage through doors and windows for the bloodlines in a negative pressure room.

Machines and patients can be separated from each other by creating temporary and portable wooden or glass walls. In case patients in ICU need dialysis; Multidisciplinary discussions by utilizing a mode of video conferencing can minimize the doctors and staff traffic to the patient's room. However, despite taking all these safety measures to protect staff and doctors-never ever compromise the safety of patients [8-13]. Other measures include home-based Dialysis, assisted home dialysis, flexibility empowerment, and home biochemical controls are the few modalities that are accepted as an alternative to hospital-based dialysis. Despite the logistic benefits, all of these modalities require extensive practice and care towards patients before they can become self-sufficient to administer dialysis at home. It requires multiple hand-on workshops with patients directly to make them adept and answer all the queries. Furthermore, telemedicine can be used to treat these patients remotely that is cost-effective, but this transition requires digital advancement and extensive training for healthcare workers along with the patients so that they can master the skills properly [9-15].

In developing countries particularly, patients are reluctant to use these techniques as they've got very limited knowledge and resources, unable to meet the exact demands of the process. Technology is not available everywhere in these countries so, telemedicine and the goals it promises cannot be achieved in remote areas [10-16]. In a study regarding the initial impact of the COVID-19 pandemic on the dialysis patients in Renmin Hospital, Wuhan University, it was found that 37 patients on dialysis (out of 230 patients) contracted COVID-19 while 4/33 staff members caught COVID-19 infection (14th January -17th February 2020). Sadly, six of these patients had to face death owing to the COVID-19 infection [15]. In another study in Italy, in a satellite HD unit, eighteen out of sixty patients were infected with COVID-19 within a short time of just one week. Luckily, no staff member got infected during that period. At another hospital, four patients contracted 
COVID out of 170 patients. Luckily, there too, the staff members were not affected [15]. Watnick and the team have formulated measures that they had followed at the outpatient dialysis clinic to curtail the spread of COVID-19 infection in the outpatient dialysis settings in the USA [17].

The role of top management in the hospital is of paramount importance in curtailing the menace of transmission of COVID-19 infection at a dialysis clinic. Management should be in close collaboration with the dialysis unit to safeguard both patients and the working staff members. In charge of the dialysis unit and hospital management should be open to the latest updates and action plans according to evolving guidelines [18]. There should be no visitor policy at the dialysis unit. Patients receiving regular dialysis should be educated regarding the importance of staying at home and social distancing measures. Their family members also need to be educated regarding the pivotal role of hand hygiene, and timely reporting of any suspicious symptoms. Family members should themselves strictly implement the safety norms needed to sop transmission of COVID within and from outside their homes. Personal or private transportation should be the means to reach to the dialysis unit [20]. Staff members should be following strict COVID safety measures such as hand hygiene, timely and safe disposal of medical waste, and most importantly proper use of PPE. Dialysis staff should be actively screened for temperature along with any suspected symptoms before, and after shifts to curtail chances of spread of COVID infection. Moreover, a policy should always be at hand, as to how to cope with the shortage of PPE in times of non-availability [17-21].

Apart from these, the patients who have contracted COVID-19 should have a separately assigned dialysis shift ideally. Furthermore, symptomatic patients should be treated at a separate row of dialysis machines [19-22]. The dialysis center must have a designated waiting area with signs posted on the importance of hand hygiene and respiratory hygiene [19-22]. In charge of dialysis center should ensure availability of alcohol-based hand wash, tissues, regular cleaning of chairs after each patient leave the waiting area, and regular and safe cleaning of trash cans [21-24]. It is important to continue health services to the patients in dire need of new vascular access placement, hence, arteriovenous fistula or grafts and Peritoneal Dialysis catheters should be carried on as scheduled. Moreover, due to the uncertain situations that may arise at any time, the patients should be briefed regarding simple measures including limiting the quantity of daily fluid and diminished potassium intake [20-25]. Additionally, they should have potassium-binding agents with them in case of missed dialysis. Lastly, those who are having a home dialysis facility should be encouraged to keep arranged extra dialysis supplies at home to cope with the shortage of supplies chain in lockdowns. In a nutshell, social distancing, strict hygienic measures, and proper patient and family members education is the key to cope with challenges faced by dialysis patients in COVID era [23-30].

\section{Conclusion}

COVID-19 is has put the whole world in a challenging situation. It has affected all types of health care facilities globally. There is a great deal of risk of exposure of dialysis patients while they receive renal replacement therapy in hospital settings. Strict hygienic measures along with judicious patient scheduling are needed. The division of duties among staff should be flexible to avoid unnecessary stress on part of staff members and management to keep the smooth continuity of dialysis services.

\section{References}

1. Fu D, Yang B, Xu J, Mao Z, Zhou C, et al. (2020) COVID-19 Infection in a Patient with End-Stage Kidney Disease. Nephron 144(5): 245-247.

2. Zhou F, Yu T, Du R, Fan G, Liu Y, et al. (2020) Clinical course and risk factors for mortality of adult inpatients with COVID-19 in Wuhan, China: a retrospective cohort study. Lancet 395(10229): 1054-1062.

3. Pan XW, Xu D, Zhang H, Zhou W, Wang LH, et al. (2020) Identification of a potential mechanism of acute kidney injury during the COVID-19 outbreak: a study based on single-cell transcriptome analysis. Intensive Care Med 46(6): 1114-1116.

4. Iqbal N, Mahmud US, Yunus H, Malik M, Shah S, et al. (2021) Utility of telemedicine in ophthalmology clinic during COVID-19 era. Biomedical Research and Clinical Reviews 3(3): 1-3.

5. Adapa S, Aeddula NR, Konala VM, Chenna A, Naramala S, et al. (2020) COVID-19 and Renal Failure: Challenges in the Delivery of Renal Replacement Therapy. J Clin Med Res 12(5): 276-285.

6. Hui DS, E IA, Madani TA, Ntoumi F, Kock R, et al. (2020) The continuing 2019-nCoV epidemic threat of novel coronaviruses to global health - The latest 2019 novel coronavirus outbreak in Wuhan, China. Int J Infect Dis 91: 264-266.

7. Zhang G, Hu C, Luo L, Fang F, Chen Y, et al. (2020) Clinical features and short-term outcomes of 221 patients with COVID-19 in Wuhan, China. J Clin Virol 127: 104364.

8. Balla M, Merugu GP, Patel M, Koduri NM, Gayam V, et al. (2020) COVID-19, modern pandemic: a systematic review from a front-line health care providers' perspective. Journal of Clinical Medicine Research 12(4): 215-229.

9. Ronco C, Navalesi P, Vincent JL (2020) Coronavirus epidemic: preparing for extracorporeal organ support in intensive care. Lancet Respir Med 8(3): 240-241.

10. Iqbal N, Ali M, Ali T, Iftikhar M J, Kala M S, et al. (2020) Telemedicine in Urology Clinic in COVID Era and the Inherent Challenges in Developing Countries: Review Article. J Biol Today's World 9(11): 001-003.

11. Brunori G, Reboldi G, Aucella F (2021) Lessons Learnt during the COVID-19 Pandemic: For Patients with End-Stage Renal Disease, We Should Prioritize Home-Based Treatment and Telemedicine. Kidney Blood Press Res 46(1): 11-16.

12. Wares JR, Lawson B, Shemin D, D'Agata EM (2016) Evaluating infection prevention strategies in out-patient dialysis units using agent-based modeling. PLoS One 11(5): e0153820.

13. Wilkie M, Davies S (2020) Peritoneal dialysis in the time of COVID-19. Perit Dial Int 40(4): 357-358.

14. Elrashdy F, Redwan EM, Uversky VN (2020) Why COVID-19 Transmission Is More Efficient and Aggressive Than Viral Transmission in Previous Coronavirus Epidemics? Biomolecules 10(9): 1312. 
15. Rombolà G, Heidempergher M, Pedrini L, Farina M, Aucella F, et al (2020) Practical indications for the prevention and management of SARS-CoV-2 in ambulatory dialysis patients: lessons from the first phase of the epidemics in Lombardy. J Nephrol 33(2): 193-196.

16. Iqbal N, Gulzar R, Riaz A, Iqbal A, Nadeem M, et al. (2021) Utility of Telemedicine in Pediatric Urology Clinic during Covid-19 Era-Mini Review. EC Paediatrics 10(2): 57-61.

17. Watnick S, McNamara E (2020) On the frontline of the COVID-19 outbreak: keeping patients on long-term dialysis safe. Clin J Am Soc Nephrol 15(5): 710-713.

18. Guan WJ, Ni ZY, Hu Y, Liang WH, Ou CQ et al. (2020) Clinical characteristics of coronavirus disease 2019 in China. N Engl J Med 382: 1708-1720.

19. Zhang W, Du RH, Li B, Zheng XS, Yang XL, et al. (2020) Molecular and serological investigation of 2019-nCoV infected patients: implication of multiple shedding routes. Emerg Microbes Infect 9(1): 386-389.

20. Bai Y, Yao L, Wei T, Tian F, Jin DY, et al. (2020) Presumed Asymptomatic Carrier Transmission of COVID-19. JAMA 323(14): 1406-1407.

21. Boyce JM, Hymes JL (2018) What we learned from Ebola: preparing dialysis units for the next outbreak. Clin J Am Soc Nephrol 13(4): 669670.

22. Bahadi A, ElKabbaj D (2020) Home Dialysis: Lessons from COVID-19 and Other Viral Outbreaks. Saudi J Kidney Dis Transpl 31(5): 1161.

ISSN: 2574-1241

DOI: 10.26717/BJSTR.2021.36.005812

Nadeem Iqbal. Biomed J Sci \& Tech Res

(c) (P) This work is licensed under Creative

Submission Link: https://biomedres.us/submit-manuscript.php
23. Gedney N (2020) Long-Term Hemodialysis during the COVID-19 Pandemic. Clin J Am Soc Nephrol 15(8): 1073-1074.

24. Kliger AS, Cozzolino M, Jha V, Harbert G, Ikizler TA (2020) Managing the COVID-19 pandemic: international comparisons in dialysis patients. Kidney Int 98(1): 12-16.

25. Tang Y, Xin Y, Deng F (2020) Prevention and management of COVID-19 in hemodialysis centers. Am J Manag Care 26(8): e237-e238.

26. Goicoechea M, Sánchez Cámara LA, Macías N, Muñoz de Morales A, Rojas ÁG, et al. (2020) COVID-19: clinical course and outcomes of 36 hemodialysis patients in Spain. Kidney Int 98(1): 27-34.

27. Kuroki Y, Hiyama K, Minami J, Takeuchi M, Shojima M, et al. (2020) The first case of COVID-19 pneumonia in a hemodialysis patient in Japan. CEN Case Rep 9(4): 404-408.

28. Bharati J, Ramachandran R, Kumar V, Kohli HS (2020) COVID-19 pandemic in limited-resource countries: Strategies for challenges in a dialysis unit. Nephrology (Carlton) 25(10): 803.

29. Najafi MT, Abbasi MR, Dehghan Manshadi SA, Rahimzadeh S, Shojamoradi MH (2020) Surveillance and Isolation Based Strategies to Preven COVID-19 in a Dialysis Center of Tehran, a Customized Approach. Iran J Kidney Dis 14(4): 321-322.

30. Kliger AS, Silberzweig J (2020) Mitigating Risk of COVID-19 in Dialysis Facilities. Clin J Am Soc Nephrol 15(5): 707-709.

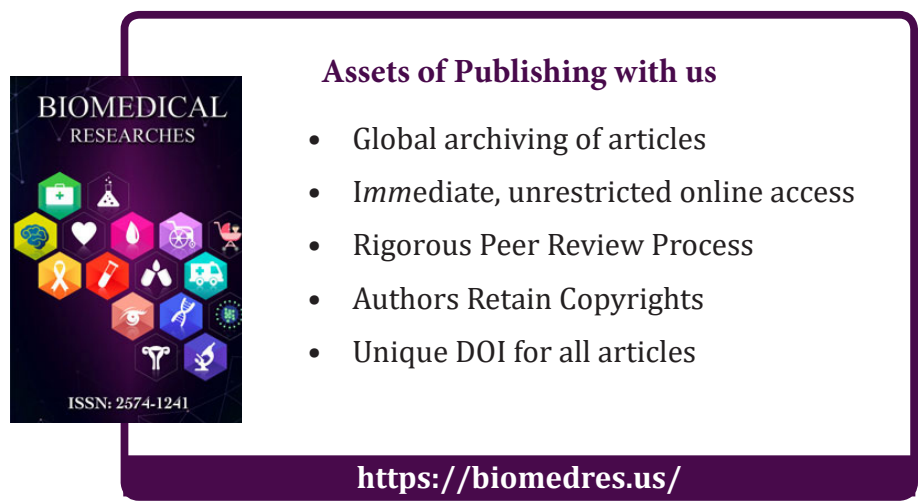

